\title{
NOISE POLLUTANTS IN AGRICULTURAL MACHINERY DRIVERS CABIN
}

\author{
Retta Zewdie, Pavel Kic \\ Czech University of Life Sciences Prague \\ zewdie@tf.czu.cz,kic@tf.czu.cz
}

\begin{abstract}
Agricultural machineries are among those having the negative features with high noise emissions, especially in the vicinity of operation routes and the driver's cabin. An option for reducing this load, at the first place, is the necessity to specify the source of the noise. The main sources belong to rolling noise and the noise of the drive power of the farm machineries, significantly, the noise of vehicle propulsion. To these important resources, it is necessary to add secondary noise sources such as concomitantly induced noise from the brakes, operational velocity, frequent stop and kick-off, safety equipment, local radio, etc. The size of these adverse effects also depends on the type of the traction, route guidance, features of the terrain, technical conditions of vehicles and transport routes. In this research paper, the authors examine the noise pollutants appearing in the drivers' cabin during their performance through careful measurements. The research was conducted on combine harvesters and tractors. The core finding of this research is the presumption of the cause of the changes in noise pollutants based on the collected data.
\end{abstract}

Key words: acoustics, acoustic signals, human health, hearing sensation.

\section{Introduction}

High incidence of noise and long-term stay in it often causes permanent consequences to human health. Numbers of researchers came to a conclusion that noise measurement in time of operation is the cardinal issue as part of the working conditions. Mobile technologies and environment interactions are closely related with strong effect on the health problems of drivers due to high noise level pollutants caused by tyres, engine rotations, chassis, threshing systems, engine drives, and the harvesting performance by itself. In this research paper, the results of the measurements are to review the noise levels of farm machineries and equipment during their performance; the findings can be used as a basis for scientific analysis and evaluation of the disturbances formed. It has also an approach to reduce noise and effectively fight for environmental protection signal. The volume of noise or the noise level, which is measured in $\mathrm{dB}$, expresses a temporal change in the pressure, which is exerted on the eardrum that is disturbing the human ear, causing hearing damage, even cardiovascular disease and hinders performance at work.

Researchers [1] have come to a conclusion that the amount of discomfort depends on the magnitude, frequency, direction and also the duration of the exposed noise in the cabin. The increases and decreases of the engine rotations, which will affect the driver's performance, at the same time giving stress to the driver due to generated noise, are specifying the correlation between the noise annoyance level and engine rotation. In a research conducted by [2], MF399 tractor cabins and a closed back cab with two state sound pressure levels were studied and tested, and the results demonstrated that tractor cabs have a significant impact on reducing the noise level in an open cabin by $\mathrm{dB} 3$. At the tractor cabin with open windows, and when windows are closed, significant variations in the noise level with opened cabin increase are observed. Long exposures to high noise levels and all-body vibrations are the major factors of risk to the workers' health and safety. In the scientific paper [3] is described accurate vibro-acoustic investigation of the machine, based on the integration of noise and vibration tests and numerical analyses, a reduction of the noise level at the driver's ear position of about $3 \mathrm{~dB}$, with the result of significant decrease of the vibrations transmitted into the cabin.

The research conducted by [4], indicates that the noise level of MF285 tractor, in 2,250 rpm engine speed, was $90 \mathrm{~dB}$, which in comparison with the standard value, $85 \mathrm{~dB}$, is dangerous for the operator's ears. The noise emitted by the tractor in three gears $(2,3$ and 4$)$ and three speeds $(1,500$, 1,950 and 2,250 rpm) was measured and then analysed statistically. The result showed that the speed of the engine has a pivotal role in the production of noise. Noise reduction techniques are used and applied by [5] in reducing the cabin noise level in the four cylindered engine driven tractor. Based on the 77/311/ECC driver-perceived noise level measurement standard, the present noise level in the tractor was estimated reaching up to $88 \mathrm{~dB}$ and the main frequency components of the noise sources are the engine rotating speed and its harmonics. As the result, the total noise level based on the EEC 
standard in the cabin is reduced from $88 \mathrm{~dB}$ to $80 \mathrm{~dB}$, which quite satisfies the EEC noise regulation level. In a paper presented by [6], the study on the structural-borne noise from the cabin structural vibration generated by the engine of the vehicle is performed. Similar interpretation was deducted in the research presented by [7]. The paper investigates the effect of the gear ratio and engine rotation speed on acoustic noise of John Deere 1055I combine harvester. The experiments were done based on the sound international standards ISO 5131, ISO 7216 and the World Health Organization considering different levels of the engine rotation speed $(1,800$ and 2,500 rpm), gear ratio $(1,2$ and $3 \mathrm{H})$ and distance from the driver ear $(10 \mathrm{~cm}, 7.5 \mathrm{~m}$ and $20 \mathrm{~m})$. Analysis of variance showed that the interactions of the engine rotation speed and gear ratio had significant effects on the emitted sound level from the harvester. It was also observed that with increasing the distance from the driver's ear, the sound level was reduced due to the effects of ambient on noise damping. In the position of the driver's ear, the sound levels were higher than the standard level of $85 \mathrm{~dB}$ in all gear ratios and engine rotation speeds. Therefore, the machine operator must use ear protection and the machine manufacturers should reduce the intensity of sound, which is emitted to the driver cabin. Researchers [8] gave strong emphasis on noise and vibration among the most important design criteria for agricultural machinery cabins. In this context, experimental analysis procedures for rapid prototyping and prediction models for early design assessment are crucial. In their papers, the sound quality inside a tractor cabin mocks up when the engine is fuelled with different biodiesel/diesel fuel blends, the influence of the chemical properties of biodiesel has been correlated to the sound quality metrics, i.e. loudness and roughness, and affecting the influence on the comfort of the tractor driver cabin. It has been found that the cetane number and the unsaturation degree of biodiesel are strongly related to loudness, whereas viscosity and the unsaturation degree are strong indicators of roughness. Finally, to predict loudness and roughness is based on the biodiesel chemical properties, which is one of the main concerns for vehicle cabin comfort.

\section{Materials and methods}

The authors performed the research on five agricultural machineries; specifically, two combine harvesters and three tractors. Detail category was denoted by the type of machineries. For the research implementation, the authors applied a Claas $450 \mathrm{AC}$ harvester, which is a German brand, E 517 (non AC) East German brand harvesters. The other three farm machineries were the tractors Case IH, Zetor Z7045 and Zetor Z7711.

The data collections were carried out roughly at hot climate conditions in the summer harvest time of 2015 and 2016. The basic measuring device for measuring the noise level is the sound level meter, with the advent of digital technology, with more complex devices of digital technology, the frequency analyser in real time to specific sound frequencies and levels. The basic function of the sound level meter is converting the audio signal into an electrical signal.

Data on the noise level conditions in farm machineries drivers' cabin were collected from the measurement devices, which are installed on the dashboard of the respective vehicles. The noise level measurements were conducted by the UNITEST Sound Level Meter 93411capacitor microphone and measuring ranges: $30-100 \mathrm{~dB}$ or $65-135 \mathrm{~dB}$, measurement accuracy $\pm 2 \mathrm{~dB}$, resolution $0.1 \mathrm{~dB}$, during the measurement used frequency evaluation filter $\mathrm{A}$, time evaluation slow $(1.5 \mathrm{~s})$, frequency range $30 \mathrm{~Hz}$ to $12 \mathrm{kHz}$. The sound lever meter is a produce of Ch. BEHA GmbH, Germany. All data were measured continuously and stored at intervals of one minute to the measuring instrument ALMEMO 2590-9, which is a produce of Ahlborn GmbH, Germany, depending on the time needed for the measurement (from 94 to 115 minutes). The instantaneous value measured every minute was stored for the entire measurement period. All measurements were five in total.

\section{Results and discussion}

The mean values including the standard deviation were calculated from the results of measurements for each of internal noise level parameters in the driving cabins. The principal results of noise level in both combine harvester driver cabins of E517, Claas 450 and three tractor driving cabins of the tractor Case IH, tractor Zetor Z7045 and Tractor Zetor Z7711 are summarized and presented in Table 1. The data represent the noise level pollutants in the operator's driving cabin. 
Results of measurements of noise level $\mathrm{dB}$ (A) in driving cabins of farm machineries

\begin{tabular}{|c|c|c|c|c|c|}
\hline Model & E517 & Claas 450 & Zetor 7711 & Case IH & Zetor 7045 \\
\hline Mean Val. & 82.5 & 81.6 & 84.3 & 72.8 & 83.2 \\
\hline St. Dev. & 1.6 & 3.0 & 5.9 & 3.2 & 5.4 \\
\hline Minimum & 76.9 & 60.6 & 50.5 & 64.6 & 61.1 \\
\hline Maximum & 87.6 & 86.3 & 91.7 & 79.5 & 90.9 \\
\hline Median & 82.7 & 82.1 & 85.4 & 71.8 & 84.5 \\
\hline
\end{tabular}

Table 2 shows the statistically significant data obtained for comparison in all five farm machineries driving cabins. The data are mean values \pm SD. Different letters $(a, b, c)$ in the subscript are the sign of high significant differences (ANOVA; Tukey HSD Test; $p \leq 0.05$ ).

Based on the result of the measurement and statistical evaluation, the lowest noise level was measured in the Case IH tractor $L_{A}=72.8 \mathrm{~dB}(\mathrm{~A})$. For the comparison, the noise level in the cabin of the combine harvester E517 $L_{A}=82.5 \mathrm{~dB}(\mathrm{~A})$, Claas $450 L_{A}=81.6 \mathrm{~dB}(\mathrm{~A})$ and the tractors of older models Zetor Z7045 $L_{A}=83.2 \mathrm{~dB}(\mathrm{~A})$. The highest noise level was measured in the driver's cabin of Zetor Z $7711 L a=83.4 \mathrm{~dB}(\mathrm{~A})$. The noise level difference between the two types of tractors Zetor Z7045 and Z7711 is not statistically significant.

Table 2

Statistical parameters of noise level measurement of farm machineries driving cabins

\begin{tabular}{|c|c|}
\hline Cabin of vehicle & $\boldsymbol{L}_{\boldsymbol{A}} \pm \mathbf{S D}, \mathbf{d B}(\mathbf{A})$ \\
\hline E517 & $82.5 \pm 1.6^{\mathrm{a}}$ \\
\hline Claas 450 & $81.6 \pm 3.0^{\mathrm{a}}$ \\
\hline Zetor 7711 & $84.3 \pm 5.9^{\mathrm{b}}$ \\
\hline Case $\mathrm{IH}$ & $72.8 \pm 3.2^{\mathrm{c}}$ \\
\hline Zetor 7045 & $83.2 \pm 5.4^{\mathrm{a}, \mathrm{b}}$ \\
\hline
\end{tabular}

The nature of description of the Claas 450 harvester graph in Figure 1 exhibits to correspond to the 77/311/ECC driver-perceived noise level measurement standard. Uphill drives showed a slight increase of noises of the values indicated on the graph 1, 3 and 5; whereas the lower values are corresponding to the downhill drives on 2, 4 and 7. Sections 6 and 8 characterize a plane ride in the farm field. The final measurement was terminated by downhill drive referred by point number 9 .

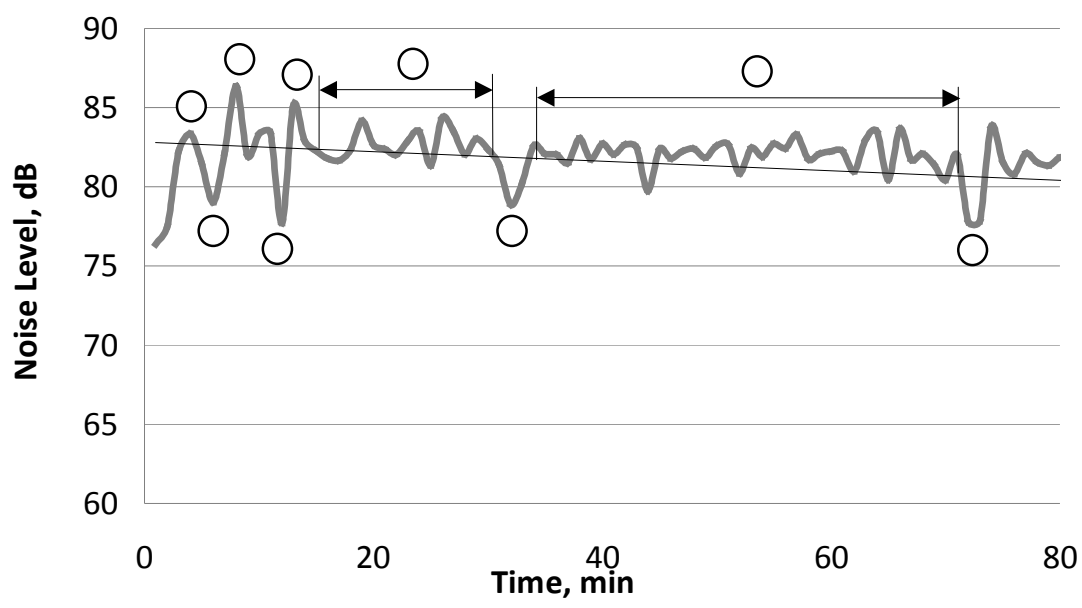

Fig. 1. Noise level measurement in combine harvester Claas 450 driving cabin

Figure 2 characterizes the noise level measurement during wheat harvest. The first thirty minutes indicated by 1 correspond to the plane ride, whereas points 2 and 3 refer to the downhill drive. Peak point number 4 exhibits the point of grain emptying from the container. The section indicated as number 5 denotes a plane ride harvesting performance. Similar patterns are obtained through GPS 
records where harvesting was observed, points 6 and 7 indicating the downhill and uphill drives respectively up to point 8 , where the harvester stopped, followed by grain emptying at point number 9 .

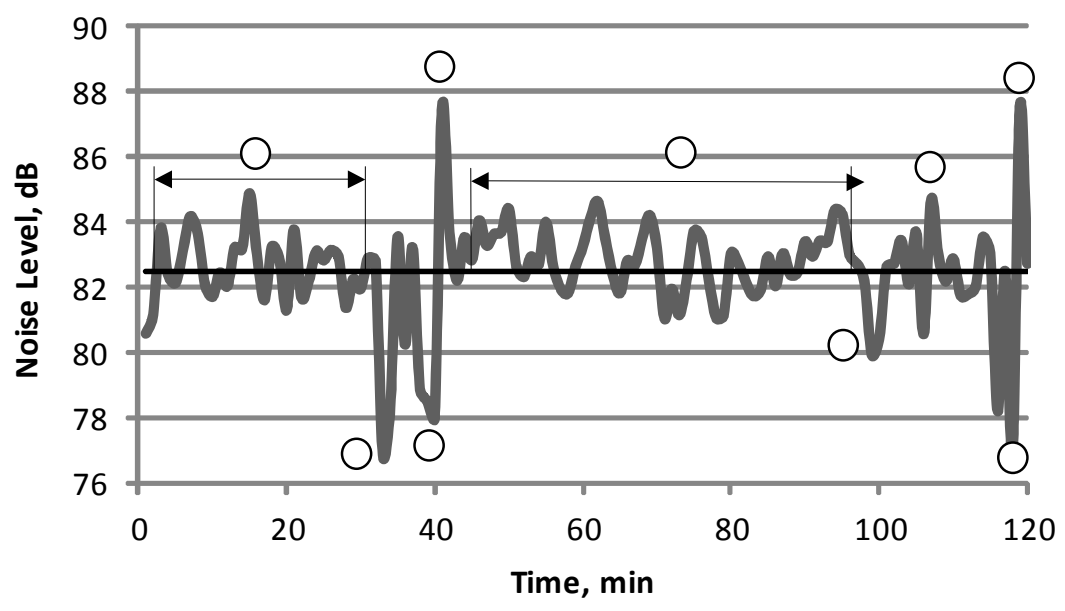

Fig. 2. Noise level measurement of E517 harvester driving cabin

Figure 3, presents the graph of the straw collecting driving process. Number 1 represents the peak for uphill drive and lower peak is consequently indicating the lower turn for downhill drive. Section 3 indicates the farm field drive with frequent turns and kick-offs with average recommended noise levels. Point 4 exhibits the uphill drive to the vicinity farm area and subsequently a drive within the village to the cattle shade as marked by number 5 . The higher noise level peaks are below $80 \mathrm{~dB}$, which is acceptable for the driver in the cabin; this could be explained by the relatively new tractor brand.

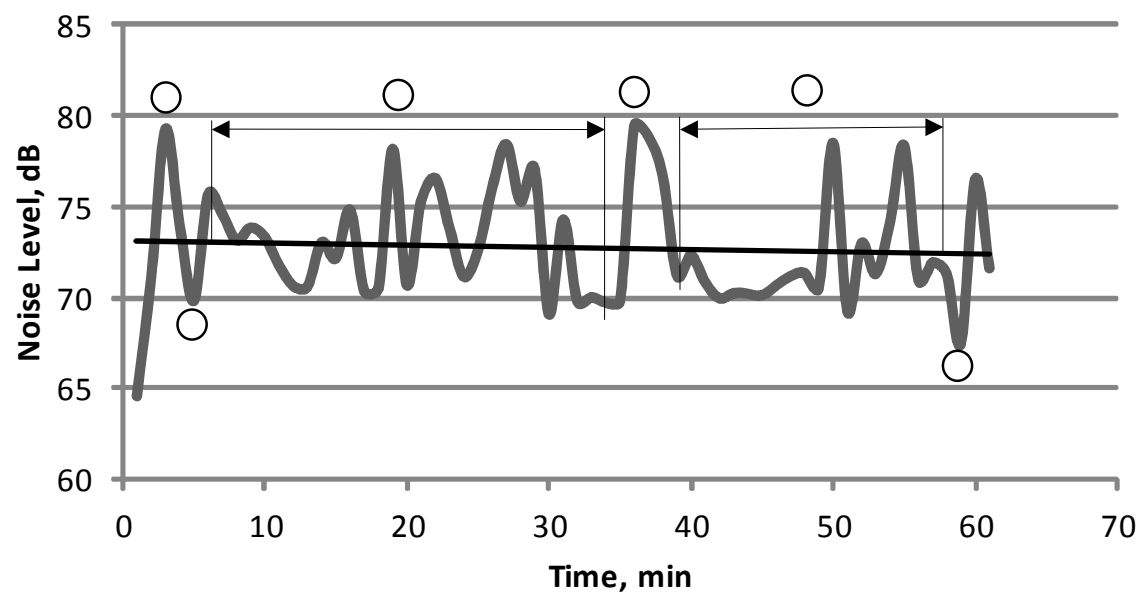

Fig. 3. Noise level measurement of tractor Case IH driving cabin

Figure 4, represents the noise level graph of straw bale collecting by the tractor Zetor Z7045. The upper peak of the noise level 1, 3, 5, 7 and 8 are beyond the recommended values, which is $\pm 90 \mathrm{~dB}$. This can be explained as places of self-loading the bales. Lower peaks 2, 4 and 7 are points for engine idling before the loading. Sections 6 and 9 are field plane rides. The occurrence of the noise level in the driving cabin for a long period can cause harm to the driver. The utilization of the noise protector on the driver ears is constructive.

Figure 5 demonstrates the sound level produced by the tractor Zetor Z7711. In the course of the measurement the tractor was used as a trailer in the harvest period of rape reed. The course of the graph indicates that section 1 was a road transport with uphill drive at peak number 2 , a downhill drive at 3 and number 4 indicating a total smooth plane ride. Peak number 5 shows the stop and 6 the place of rape seed storage for dumping. Section 7 indicates the return drive back to the harvest field. From 
the graph, it is clearly seen that the noise level approaches and even exceeds $90 \mathrm{~dB}$, which is not recommendable for the driver health.

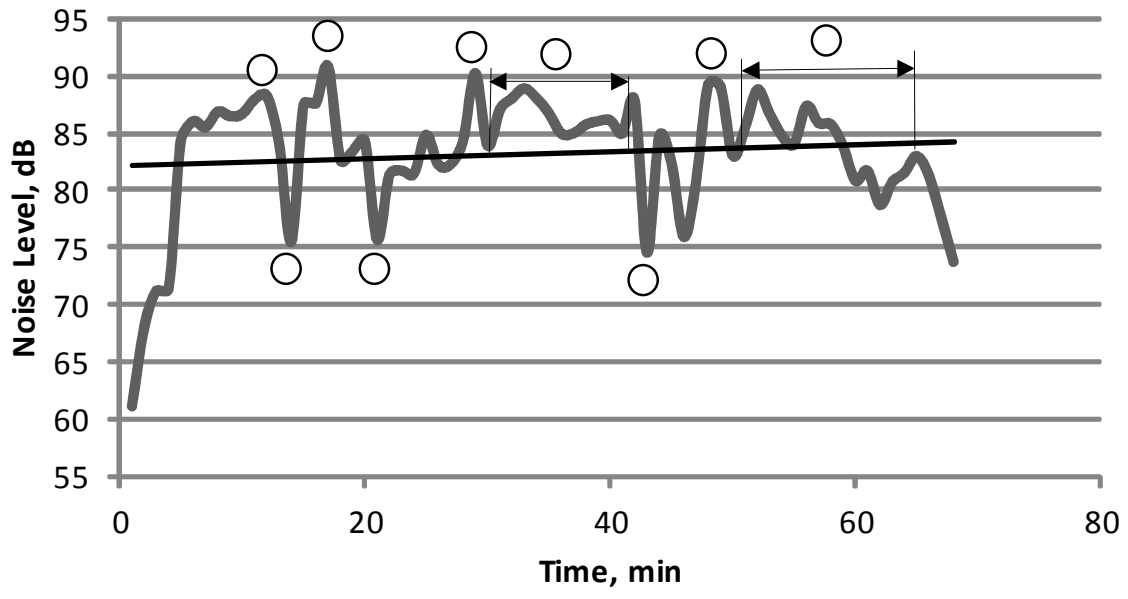

Fig. 4. Noise level measurement of Zetor Z7045 driving cabin

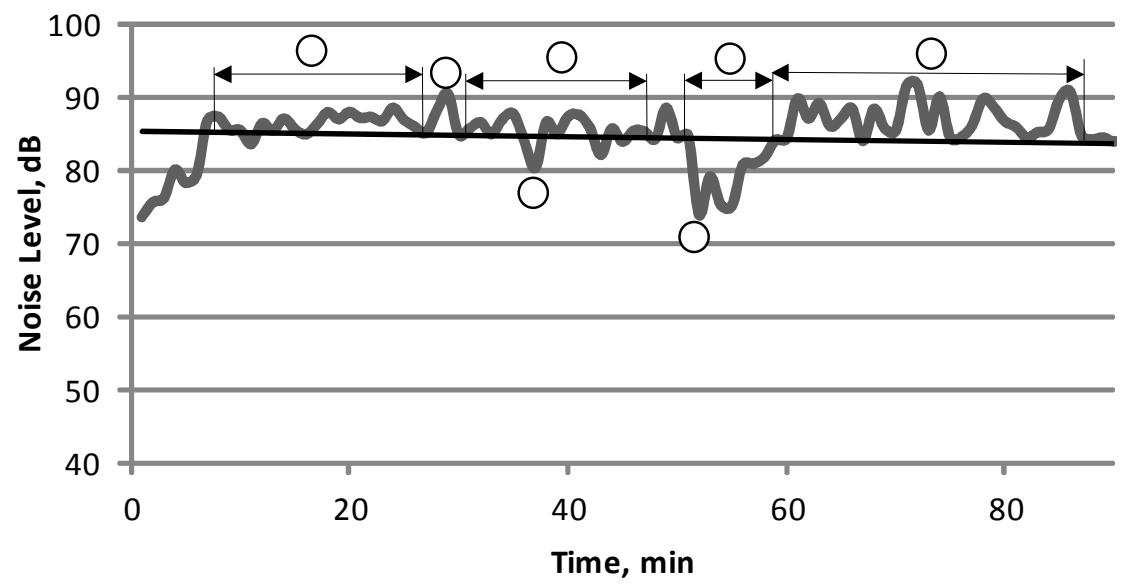

Fig. 5. Noise level measurement of Zetor Z7711 driving cabin

\section{Conclusions}

1. Farm machine driving cabins should be protected from high level noise pollutants by sealing elements like rubber seals.

2. High noise level appears by uphill drives and emptying, dumping and driving kick-offs.

3. Outdated farm machineries are not recommendable for performance accomplishment due to the engine and transmission wear out.

4. On outdated farm machineries, above $80 \mathrm{~dB}$, it is advisable to wear ear protection.

5. Agricultural machinery drivers must take into consideration the manufacturer's instructions for safe operation particularly related to noise pollutants affecting the health of the operator.

\section{References}

1. Junoh A.K., Nopiah Z.M., Muhamad W. etc. A Study on the Effects of Tyre Vibration to the Noise in Passenger Car Cabin. AMO - Advanced Modelling and Optimization, 2011. Vol. 13, pp. 53-69.

2. Mofrad F.E., Lar M.B., Kohan A. Reduce noise in the cab of the tractor MF399 sugar transport operation. Article. Agricultural Engineering International. CIGR Journal Vol. 14, 2012, pp. 50-55.

3. Carletti E., Miccoli G. Vibroacoustic optimization of a tractor CAB (Conference Paper). CNRIMAMOTER, National Research Council of Italy, Ferrara, Italy. 
4. Jaliliantabar F., Rabbani H., Lorestani A. etc. Mechanics of Agricultural Machinery Department, Razi University of Kermanshah, Iran.

5. Pinzi S., Cubero-Atienza A.J., Dorado M.P. Vibro-acoustic analysis procedures for the evaluationof the sound insulation characteristics of agricultural machinery cabins (2003) Journal of Sound and Vibration, 266 (3), pp. 407-441.

6. Lee J., Kim W. etc. Noise reduction of cabin in four-cylindered engine driven tractor (Conference Paper). CAE Technology Group, Production Engineering Center, LS Cable, Ltd., Anyang-Si, Kyunggi-Do, South Korea.

7. Cao J., Dai L. Industrial Systems Engineering, University of Regina, 3737 Wascana Parkway, Regina, Sask. S4S 0A2, Canada.

8. Jahanbakhshi A., Ghamari B., Heidarbeigi K. Agricultural Engineering International: CIGR Journal Volume 18, Issue 3, 2016, pp. 106-112. 